Bangladesh J. Bot. 44(1): 15-22, 2015 (March)

\title{
AMELIORATION OF SEED YIELD, OIL CONTENT AND OIL QUALITY THROUGH INDUCED MUTAGENESIS IN SESAME (SESAMUM INDICUM L.)
}

\author{
Tamina Begum*1 and Tapash Dasgupta \\ Department of Genetics and Plant Breeding, Institute of Agricultural Science, \\ University of Calcutta, 51/2, Hazra Road, Kolkata-70019, India
}

Key words: Induced mutagenesis, Oil content and quality, Seed yield, Sesame

\begin{abstract}
Thirty mutant lines selected from 3 widely adapted genotypes of sesame viz. Rama, SI 1666 and IC 21706 (ten from each of the three genotypes), developed by induced physical ( $\gamma$-rays) and chemical (EMS) mutagens, were evaluated against their respective control genotype for yield and its important attributes in $\mathrm{M}_{4}$ generation to reveal the ramification of mutagens for disclosing the magnitude of variation among mutants in advance generation and also to identify the promising positive mutants to refurbish new improved varieties of sesame. Mutants professing higher seed yield were evaluated for oil quantity and quality. All selected mutant lines evinced improved seed yield over their respective controls. Irrespective of the genotypes highest yield was recorded in the line induced by $0.5 \%$ EMS. Based on mean seed yield and its components, selected 10 superior mutants, also possessed high oil percentage with a better oil profile having relatively more polyunsaturated fatty acid content, specially linoleic acid, than the control, indicating potentiality of mutation breeding to restructure plants with high yield, improved oil percentage and quality.
\end{abstract}

\section{Introduction}

Sesame, an important oil-yielding crop is a popular cooking medium used throughout India. The crop demonstrates good promise in the State of West Bengal also, because of higher productivity than national average. India ranks low in sesame productivity mainly due to dearth of high yielding varieties. Narrow gene pool in the available germplasms demands the need of crop restructuring for higher productivity. On the other hand, development of superior varieties may foster higher production of sesame in the country both through horizontal and vertical expansion and can obviously narrow down the huge demand-supply gap of oilseeds. Creation of variability transpires to be primary step to get desirable types. Mutation breeding has long been known as a potential technique to unlock additional genetic variability for supplementing conventional crop breeding methodology. Mutagenesis offers a unique scope for creating variation, as it may alter even those genes that are common to all the varieties of a species. Induced mutation has been extensively and successfully used for the improvement of many crops including oilseed crop like sesame (Das and Haque 1997, Li and Chen 1998, Mehta and Singh 1998, Sorour et al. 1999, Govindarasu and Ramamoorthi 2000, Sheeba et al. 2003, 2005, Chowdhury et al. 2009, Diouf et al. 2010, Begum and Dasgupta 2010, 2011, 2014).

The value and utility of an oilseed crop for both nutritional and industrial purposes primarily depends upon the fatty acid composition of the seed oil. Development of cultivars with elevated contents of fatty acids could increase the utility of the oil for specific edible purposes. Therefore, high and stable oil content is a desirable trait in the breeding of improved sesame cultivars (Were et al. 2006). Out of different selections, plant breeders prefer to select those lines which exhibit high yield along with high oil content and high linoleic acid, a PUFA, as linoleic acid is correlated with other important yield traits (Begum and Dasgupta 2011). Therefore, along with seed yield, oil content and fatty acid composition are considered as important attributes in any oilseed crop.

*Author for correspondence: <tamina@live.in>. ${ }^{1}$ Present address: Central Research Institute for Jute and Allied Fibres (Indian Council of Agricultural Research), Barrackpore, Kolkata-700 120, India. 
Mutagenesis has been successfully employed to ameliorate oil content as well to engender variation in fatty acid profile of sesame. Mutants with enhanced seed oil content and/or altered fatty acid composition in sesame have been reported by many earlier researchers (Lee et al. 1984, Kang et al. 1998, Chowdhury et al. 2009, Savant and Kothekar 2011).

Against this genesis, the present investigation was designed to induce variability through mutagenic treatments of existing genotypes for boosting up the range and depth of variability. Subsequently, the extent of variability of superior individuals was assessed in terms of seed yield, oil quantity and quality.

\section{Materials and Methods}

The basic materials consisted of three diverse genotypes of sesame (Sesamum indicum L.) viz, Rama, SI 1666 and IC 21706 selected on the basis of phenotypic and seed storage protein diversity through SDS-PAGE (sodium dodecyl sulphate polyacrylamide gel electrophoresis). Genetically pure and uniform dry seeds (10 - 12\% moisture content) of each of the three genotypes were treated with 200, 400 and 600 Gy doses of gamma-rays (physical mutagen) and four concentrations of EMS (chemical mutagen) viz. 0.5, 1.0, 1.5 and 2.0\%. The detail procedure has been described by Begum and Dasgupta $(2010,2011)$.

The treated seeds were grown separately for each genotype during 2004-05 at Agricultural Experimental Farm, University of Calcutta, Baruipur, West Bengal, India representing alluvial part of coastal South Bengal $\left(22^{\circ} 21^{\prime} 56^{\prime \prime} \mathrm{N}, 88^{\circ} 26^{\prime} 14^{\prime \prime}\right.$ E) to raise $\mathrm{M}_{1}$ generation. The $\mathrm{M}_{1}$ generation was bulk harvested and $\mathrm{M}_{2}$ generation was grown. Based on superior performance, ten selected families $\left(\mathrm{M}_{2}\right)$ of each genotype were advanced to $\mathrm{M}_{3}$. In $\mathrm{M}_{3}$ ten progeny rows were raised with a single row of respective controls for each treatment. Based on yield and its component means, 10 superior mutant families were selected for each genotype. Thus, a total of 30 families (Table 1) representing 3 genotypes were advanced to $\mathrm{M}_{4}$ during 2007-08 in randomized block design with three replications.

In each generation, data were recorded for 11 agromorphological and phonological traits namely days to $1^{\text {st }}$ flowering, flower duration (days), plant height $(\mathrm{cm})$, number of branches per plant, number of capsules per plant, capsule length $(\mathrm{cm})$, internode length $(\mathrm{cm})$, number of seeds per capsule, 1000-seed weight (g), days to maturity and seed yield per plant (g). In $\mathrm{M}_{4}$ generation mean value for seed yield and yield components, as reported by Begum and Dasgupta (2011), was taken into consideration for 30 selected mutant lines to assess the performance against respective control genotypes with that of mutant populations. Irrespective of genotypes and treatments 10 superior mutants were ultimately selected in $\mathrm{M}_{4}$ generation on the basis of divergence from respective control genotypes, characterized by high yield and yield components. These 10 mutants showing distinct and desirable morphological characteristics were subjected to biochemical analysis for further selection with respect to oil quantity and quality. The oil content and fatty acid composition of selected mutants were estimated following the methods of Lee (1981) and Metcalfe and Schmitz (1961), respectively. The analysis of variance (ANOVA) was computed using the statistical software MSTAT-C, version 2.1 (Michigan State University, 1988).

\section{Results and Discussion}

In $\mathrm{M}_{4}$ generation, the analysis of variance for 11 characters revealed that mean squares were highly significant for all the traits except capsule length (Table 2) indicating the existence of high genetic variability among the mutant lines for yield and yield components. In other words, mutation induced substantial genetic variability among the lines. 
All selected mutant lines showed increase in seed yield and most of the yield components in comparison to respective controls (Table 3 ). In most cases, the mutant line no. 10 induced by $0.5 \%$ EMS, recorded highest percentage increase over control. Out of 30 mutant lines, the line no. 10, originating from genotype Rama, exhibited maximum increase in plant height and number of branches per plant; whereas line no. 10, developed from genotype SI 1666, recorded highest number of capsules per plant and seed yield per plant. The percentage increase in mutant population over control oscillated from 1.22 to $30.60 \%$ for plant height and 28.64 to $297.96 \%$ for branches per plant, while it was 7.40 to $416.50 \%$ and 8.23 to $479.43 \%$ for number of capsules per plant and seed yield per plant, respectively. Positive shift in mean values due to the enhancing effect of gamma-rays and/or EMS was also reported earlier by manyresearch workers (Khan and Wani 2006, Siddiqui et al. 2009, Pavadai et al. 2010) in other crops like green gram, rapeseed, soybean and their findings confirmed the present observation. Interestingly, mutation exhibited both advantageous and deleterious effect for mean number of seeds per capsule and 1000-seed weight, albeit maximum improvement was evident mostly in 0.5\% EMS treated mutant lines.

Out of 30 promising mutants qualified for selection in $\mathrm{M}_{4}$ generation, 13 were induced by EMS and the rest 17 by $\gamma$-rays. Among outstanding mutants, those induced by EMS especially $0.5 \%$ dose, turned out to be more promising compared to gamma-rays. This fortifies the earlier findings of Begum and Dasgupta (2010). Combining all mutagenic lines, mutant line no. 10 of each of the 3 genotypes induced by $0.5 \%$ EMS produced highest yield (Table 3). Remarkable increase in number of capsules per plant was also recorded in the same mutant line of Rama and SI 1666; while, it was line no. 7 for mutagen treated population of IC 21706. The high yielding mutagenic lines namely, line nos. 5, 9 and 10 of Rama; line nos. 3, 4, 8 and 10 of SI 1666 and line nos. 7, 9 and 10 of IC 21706 were identified as very promising and therefore, selected for biochemical analysis and further testing.

With regard to oil yield, considerable variations were observed among 10 selected mutants (Table 4). All the selected mutants exhibited higher oil content over their respective controls. The oil content of the mutants varied from 46.63 to $53.25 \%$ indicating 0.09 to $29.42 \%$ improvement over respective controls. Highest oil content was recorded in selection no. 8 , followed by selection no. 9 which were developed from the population of IC 21706 induced by $0.5 \%$ EMS (Table 4). The mutants selected from induced population of SI 1666 exhibited higher percentage increase in oil content ranging from 19.46 to $29.42 \%$ over control, while the increase was 0.09 to $7.32 \%$ and 0.12 to $10.71 \%$ in selections from mutant populations of Rama and IC 21706 , respectively. Therefore, it may be inferred based on oil quantity, that selection nos. 4 and 6 derived from 200 Gy $\gamma$-rays and $0.5 \%$ EMS treated population of SI 1666 were more desirable as these two mutants exhibited maximum percentage increase in oil content over the control genotype.

Substantial genetic variation was also recorded in fatty acid profile among the selected mutants (Table 4). The results revealed that linoleic acid was the major component ranging from 42.21 to $46.29 \%$ of the total fatty acids followed by oleic ( 35.35 to $38.56 \%$ ), palmitic ( 7.05 to $10.27 \%$ ) and stearic (2.98 to $3.44 \%$ ) acid. Four mutants namely selection no. 1 (selected from mutant line no. 5 of Rama irradiated by 400 Gy $\gamma$-rays), selection no. 5 (derived from mutant line no. 4 of SI 1666 treated by 200 Gy dose of $\gamma$-rays), selection no. 7 (selected from mutant line no. 10 of SI 1666 induced by $0.5 \%$ EMS) and selection no. 8 (developed from mutant line no. 7 of IC 21706 treated by $0.5 \%$ dose of EMS), were characterized by improvement in both oleic and linoleic acid content over their respective controls (Table 4). In general, linoleic acid content was always higher than oleic acid in all mutants. 


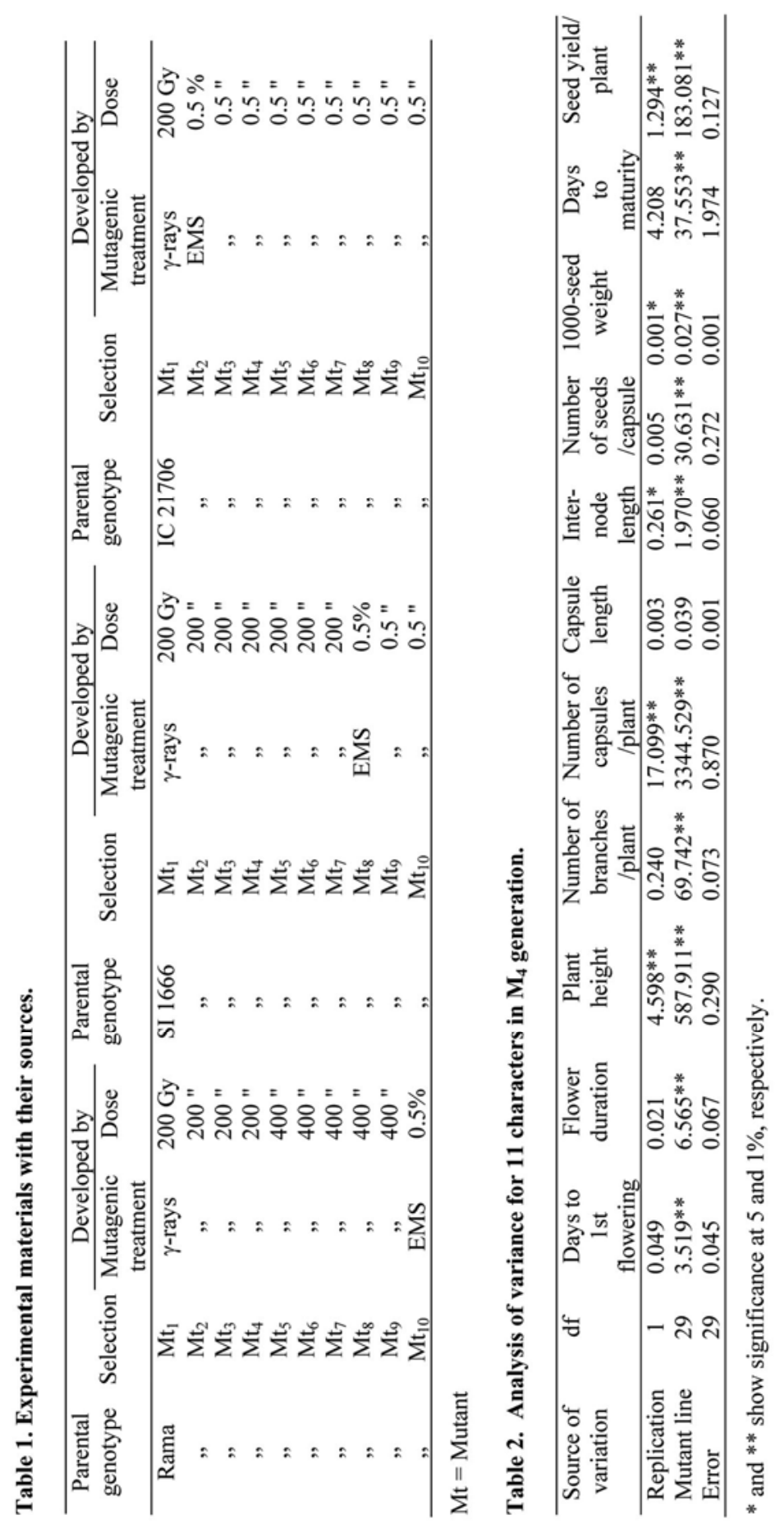




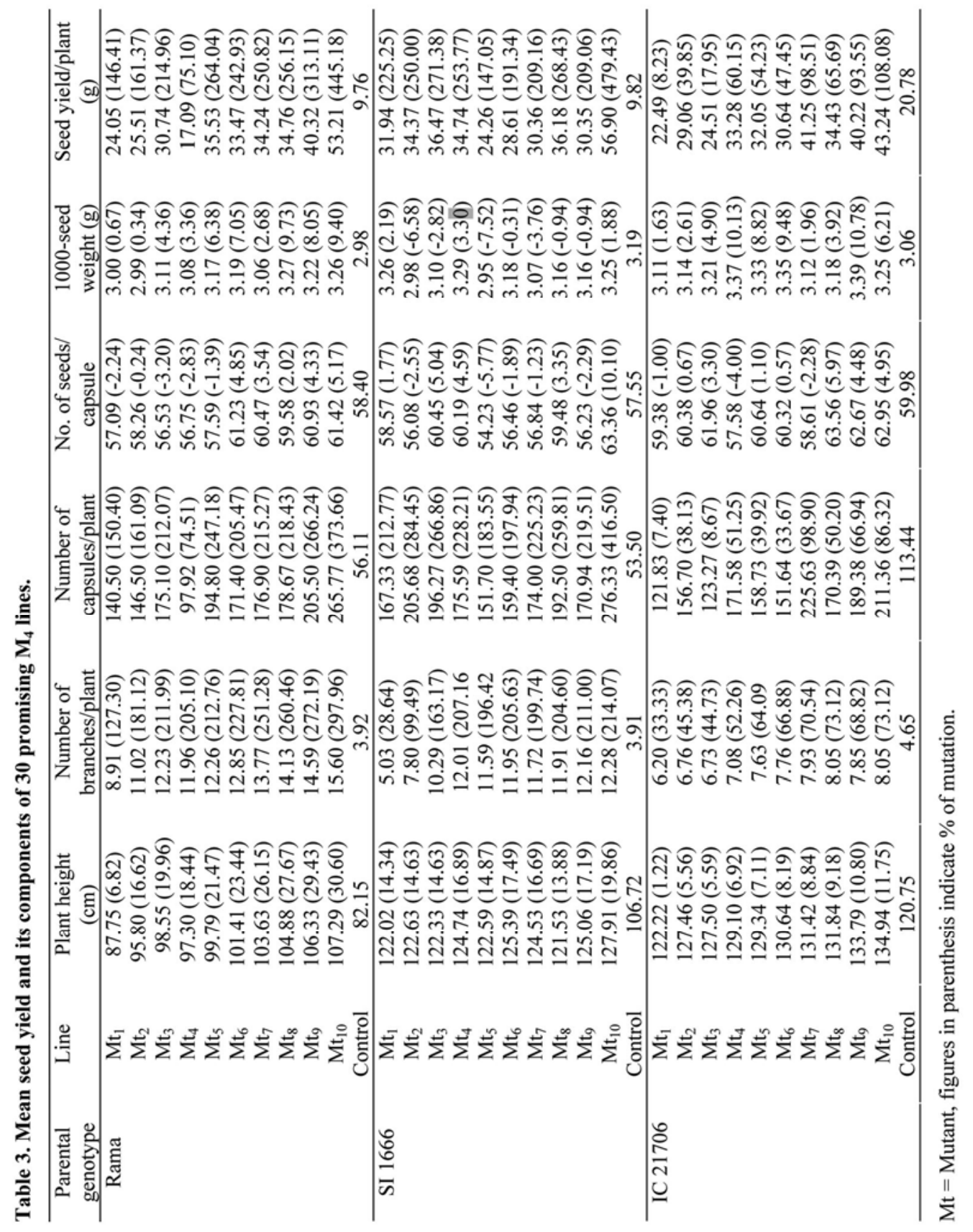




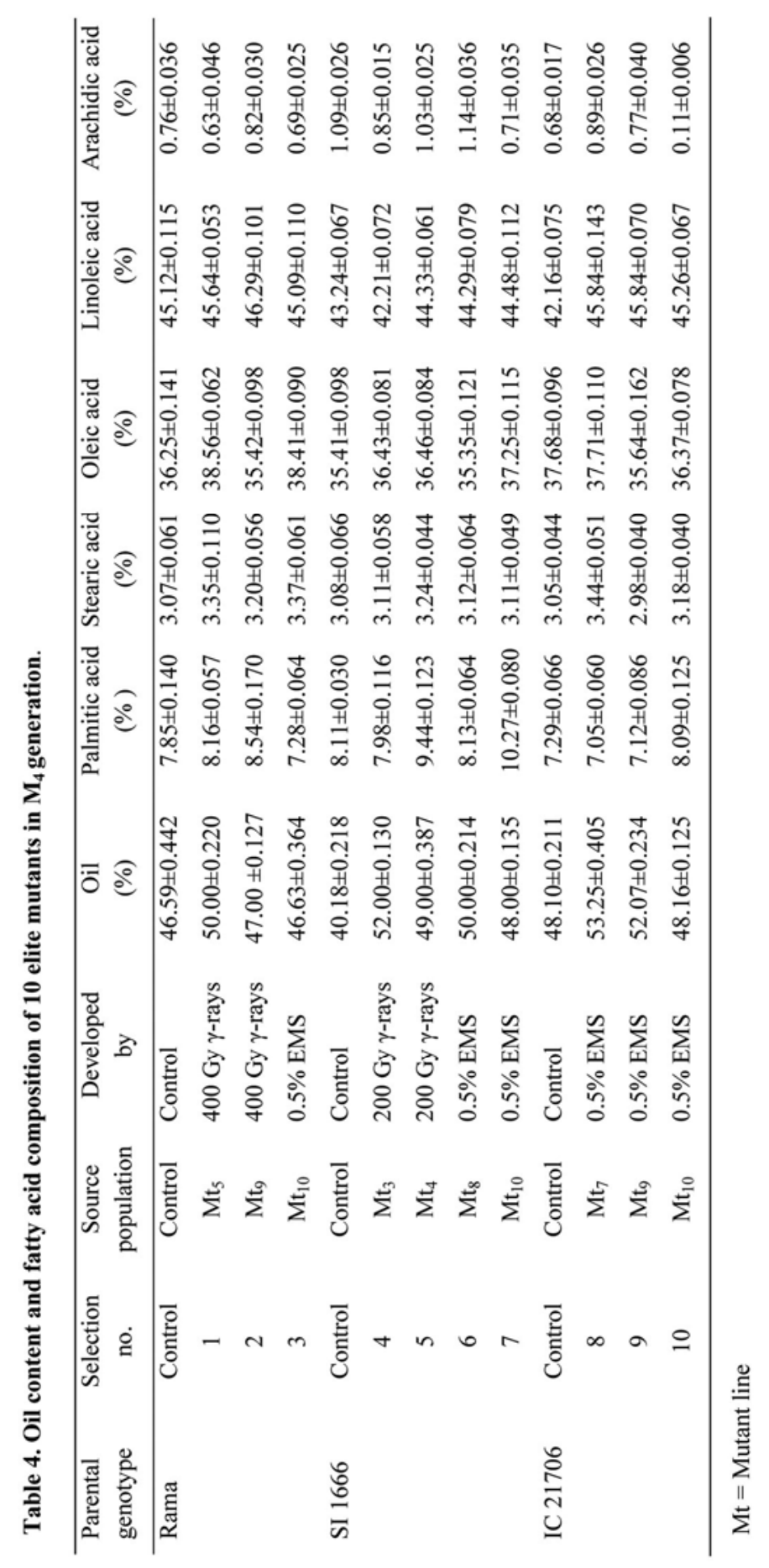


Oils rich in PUFA are more nutritious due to their ability to supply essential fatty acids. PUFA increases high density lipoprotein which removes cholesterol from arteries and thus reduces the risk of heart disease (Sengupta and Das 2003). Therefore, the mutants having enhanced percentage of linoleic acid, a PUFA, would be beneficial for human health. In the present study, mutants having improved linoleic acid would be most preferable to the plant breeders, as linoleic acid is positively correlated with seed yield and oil content (Begum and Dasgupta 2011). Thus selection for high linoleic acid containing lines would have a correlated response in high yield. A marginal improvement of stearic acid, palmitic acid and arachidic acid content were also observed in the mutants. The increased percentage of palmitic acid, stearic acid, oleic acid, linoleic acid and arachidic acid content over controls ranged from $0.25-26.63 \%, 0.97-12.79 \%, 0.08-6.37 \%, 1.15$ - $8.73 \%$ and $4.59-30.88 \%$, respectively.

Mutation breeding helps in creating variability not only in agromorphological traits like yield and yield components, but also a better oil quality profile can be achieved through this methodology in an oilseed crop like sesame (Lee et al. 1984, Kamala and Sasikala 1985, Kang et al. 1998, Chowdhury et al. 2009, Ong'injo and Ayiecho 2009, Savant and Kothekar 2011). Mutants with altered seed oil fatty acid profile are usually the result of a mutation at a single locus (Velasco and Fernandez-Martinez 2002). In the present study, 10 selected superior mutants evinced 93.55 to $479.43 \%$ superiority in seed yield as well 0.09 to $29.42 \%$ increase in oil content over controls, concomitant with improved oil quality. The seed oil of all the selected mutants was rich in linoleic acid which makes the oil nutritionally precious. Mutation breeding has thus the potentiality of genetic enhancement in terms of agromorphological and biochemical attributes, consequently, evolving new genotypes with high yield and improved nutritional quality.

\section{References}

Begum T and Dasgupta T 2010. A comparison on the effect of physical and chemical mutagenic treatments in sesame (Sesamum indicum L.). Genet. Mol. Biol. 33: 761-766.

Begum T and Dasgupta T 2011. Effect of mutagens on character association in sesame (Sesamum indicum L.). Pak. J. Bot. 43: 243-251.

Begum T and Dasgupta T 2014. Induced genetic variability, heritability and genetic advance in sesame (Sesamum indicum L.). SABRAO J. Breed. Genet. 46: 21-33.

Chowdhury S, Datta AK, Saha A and Maity S 2009. Radiation-induced two oil rich mutants in sesame (Sesamum indicum L.). Indian J. Sci. Technol. 2: 51-52.

Das ML and Haque MM 1997. Response of sesame seeds to gamma ray and EMS in $\mathrm{M}_{1}$ generation. Bangladesh J. Bot. 26: 75-78.

Diouf M, Boureima S, Diop T and Çağirgan M 2010. Gamma rays-induced mutant spectrum and frequency in sesame. Turk. J. Field Crops 15: 99-105.

Govindarasu R and Ramamoorthi N 2000. Increased genetic variability following hybridization and mutagenesis in sesame. Indian J. Genet. 60: 251-253.

Kamala T and Sasikala S 1985. Gamma-ray and colchicine induced mutants of TMV5' and 'IS 103' Sesamum. Indian J. Agric. Sci. 55: 151-155.

Kang CW, Rho JH, Lee SW, Park CB, Lee J, Lee ST, Oh MK and Park K 1998. A high oil, linoleic fatty acid content and yielding new sesame mutant variety "Jangbaeckkae". RDA Journal of Industrial Crop Science 40: 83-88.

Khan S and Wani MR 2006. Induced mutations for yield contributing traits in green gram. Int. J. Agri. Biol. 8: $528-530$.

Lee JI, Kang CW and Lee ST 1984. Breeding of sesame for oil quality improved. III. Variation of fatty acid composition in gamma ray irradiated $\mathrm{M}_{2}$ mutant populations. Research Report of the Office of Rural Development, South Korea Crop 26: 134-143. 
Lee SK 1981. Methods for percent oil analysis of Avocado fruit. California Avocado Society Yearbook 65: 133-141.

Li Y and Chen QM 1998. Induction of male sterility mutation in sesame (Sesamum indicum L.) and a preliminary study of the genetics of the mutation. Chinese J. Oil Crop Sci. 20: $24-27$

Mehta AK and Singh CB 1998. A gamma irradiated dichotomously branched plant type in Sesamum. Plant Sci. 11: 233-235

Metcalfe LD and Schmitz AA 1961. The rapid preparation of fatty acid esters for gas chromatographic analysis. Analytical Chemistry 33: 363-364.

Michigan State University. 1988. User's Guide to MSTAT-C a software program for the design, management, and analysis of agronomic research experiment, MSU, USA.

Ong'injo EO and Ayiecho PO 2009. Genotypic variability in sesame mutant lines in Kenya. African Crop Science Journal 17: 101-107.

Pavadai P, Girija M and Dhanavel D 2010. Effect of gamma rays on some yield parameters and protein content of soybean in $\mathrm{M}_{2}, \mathrm{M}_{3}$ and $\mathrm{M}_{4}$ generation. J. Exp. Sci. 1: 8-11.

Savant KD and Kothekar VS 2011. Induction of variability in fatty acid profile in sesame (Sesamum indicum L.). Journal of Phytology 3: 1-3.

Sengupta K and Das PK 2003. General Overview. In: Cultivated Annual Oilseed Crops in India, $1^{\text {st }}$ edn., Naya Udyog, Kolkata, West Bengal, pp. 27.

Sheeba A, Anbumalarmathi J, Babu S and Ibrahim SM 2005. Mutagenic effect of gamma rays and EMS in $\mathrm{M}_{1}$ generation in sesame (Sesamum indicum L.). Res. on Crops 6: 303-306.

Sheeba A, Ibrahim SM and Yogameenakshi P 2003. Induced chlorophyll mutation studies in sesame (Sesamum indicum L.). Sesame and Safflower Newsletter 18: 33-38.

Siddiqui MA, Khan IA and Khatri A 2009. Induced quantitative variability by gamma-rays and ethylmethane sulphonate alone and in combination in rapeseed (Brassica napus L.). Pak. J. Bot. 41: 1189-1195.

Sorour WAI, Hussein MH and Ei-imam MA. 1999. Gamma-ray induced mutations in sesame (Sesamum indicum L.) I. Selection of useful mutants. Bull Faculty Agric University of Cairo 50: 516-531.

Velasco L and Fernandez-Martinez JM 2002. Breeding oilseed crops for improved oil quality. Journal of Crop Production 5: 309-344.

Were BA, Onkware AO, Gudu S, Welander M and Carlsson AS 2006. Seed oil content and fatty acid composition in East African sesame (Sesamum indicum L.) accessions evaluated over 3 years. Field Crops Research 97: 254-260.

(Manuscript received on 13 April, 2013; revised on 19 August, 2014) 